\title{
PRODUÇÃo E CARACTERIZAÇÃO DE CARVÃO ATIVADO PRODUZIDO A PARTIR DO DEFEITO PRETO, VERDE, ARDIDO (PVA) DO CAFÉ
}

Paulize H. Ramos*, Mário C. Guerreiro, Eliane C. de Resende e Maraísa Gonçalves

Departamento de Química, Universidade Federal de Lavras, CP 3037, 37200-000 Lavras - MG, Brasil

Recebido em 11/4/08; aceito em 2/12/08; publicado na web em 11/5/09

\begin{abstract}
PRODUCTION AND CHARACTERIZATION OF ACTIVATED CARBON PREPARED FROM PVA DEFECT COFFEE. The black, green and sour coffee defect (PVA) contributes with $20 \%$ of the total coffee production. It should be separate from the normal coffee grains in order to improve the final quality of the beverage. In this way, the present work has the objective to use the PVA reject for the production of activated carbon. The activated carbon (CA) was prepared from PVA defect using zinc chloride as activating agent. The prepared material (CA PVA) was characterized and the adsorption tests were carried out using as organic models methylene blue (AM) and reactive red (VR). The CA PVA revealed to be more efficient in the removal of the organic contaminants compared to a commercial activated carbon.
\end{abstract}

Keywords: coffee bean defect; activated carbon; adsorption.

\section{INTRODUÇÃO}

O café constitui uma das principais fontes de divisas do Brasil. Porém, o aumento da produção e a melhoria da qualidade dos cafés de outros países, associados à crescente demanda por cafés de bebida superior pelos países importadores geraram queda nas exportações brasileiras. ${ }^{1}$ A qualidade do café é um dos fatores determinantes para a boa aceitação do produto nos mercados nacional e internacional. Os grãos de cafés defeituosos estão permanentemente presentes no café produzido no Brasil devido, principalmente, ao tipo de colheita, derriça no chão e o processamento adotado pelos produtores. ${ }^{2,3}$

Os grãos defeituosos, que compreendem aproximadamente $20 \%$ da produção total de café, comprometem a qualidade da bebida quando são torrados com os grãos sadios. ${ }^{4}$ Entre esses defeitos, destaca-se a fração de defeito PVA (preto, verde, ardido) que, se separada dos grãos sadios, gera um volume de rejeitos e de perdas significativas no volume comercializado. Para minimizar o prejuízo causado pela presença dos defeitos, muitas vezes, emprega-se a diluição destes aos cafés de melhor qualidade, gerando um produto de qualidade intermediária. Uma maneira de aproveitar os rejeitos provenientes da produção de café é desenvolver novos produtos com valor agregado a partir do defeito PVA. A produção de carvão ativado (CA) apresenta-se como uma alternativa para a utilização desse rejeito.

O CA é preparado a partir de um material carbonáceo poroso que apresenta uma forma microcristalina, não grafítica e sofre um processamento para aumentar a porosidade interna. ${ }^{5}$ Materiais que possuem um alto teor de carbono, como madeira, hulha, lignina, casca de coco, grão de café, bambu, quitosana etc, podem ser convertidos em CA. ${ }^{6-8}$ Seu poder adsorvente é proveniente da alta área superficial e da presença de uma variedade de grupos funcionais em sua superfície. ${ }^{9}$ Os CA podem ser utilizados como materiais adsorventes no tratamento de água, no controle da emissão de poluentes, na purificação e armazenamento de gases, catalisadores e suportes catalíticos. ${ }^{10,11}$

A produção de CA envolve duas etapas: a carbonização do precursor em atmosfera inerte e a ativação do material carbonizado. A

*e-mail: lizhramos@hotmail.com etapa de carbonização consiste no tratamento térmico (pirólise) do precursor sob atmosfera inerte à temperatura, normalmente, superior a 473 K. É uma etapa de preparação do material na qual se removem componentes voláteis e gases leves $\left(\mathrm{CO}, \mathrm{H}_{2}, \mathrm{CO}_{2}\right.$ e $\left.\mathrm{CH}_{4}\right)$, produzindo uma massa de carbono fixo e uma estrutura porosa primária que favorece a ativação posterior. ${ }^{12} \mathrm{O}$ processo de ativação ocorre após o processo de pirólise e consiste em submeter o material carbonizado a reações secundárias, visando a obtenção de um material poroso e com elevada área superficial. A ativação consiste na retirada de componentes como alcatrão, creosoto e naftas, além de outros resíduos orgânicos que possam obstruir os poros..$^{13}$ Os carvões podem ser ativados por processos físicos, químicos ou combinação dos dois métodos. A ativação física envolve a carbonização do material e a subseqüente ativação em altas temperaturas, entre 800 a $1.100{ }^{\circ} \mathrm{C}$, sob fluxo de gases como vapor d'água, dióxido de carbono ou uma mistura desses gases. ${ }^{14} \mathrm{~A}$ ativação química consiste na impregnação do material ainda não pirolisado com agentes desidratantes, como cloreto de zinco, ácido fosfórico, hidróxido de sódio, etc. e, posteriormente, carbonização em atmosfera inerte, com temperaturas entre 400 e $900{ }^{\circ} \mathrm{C} .{ }^{15}$

Dentre as principais aplicações de CA destaca-se o emprego na remoção de contaminantes do meio aquoso, que vem sendo cada vez mais utilizado devido ao aumento da complexidade dos componentes indesejáveis presentes nos efluentes aquosos. A aplicação do CA no tratamento de efluentes está relacionada principalmente à redução de material orgânico, em especial de espécies que alteram a cor de efluentes. ${ }^{16}$ Neste trabalho, foi preparado carvão ativado a partir da fração de defeito PVA do café e o material foi testado na remoção de compostos orgânicos em água.

\section{PARTE EXPERIMENTAL}

\section{Amostras}

As frações PVA do café utilizadas na preparação dos carvões ativados foram obtidas da safra 2005/06 e fornecidas pela fazenda experimental da Empresa Brasileira de Pesquisa Agropecuária de Minas Gerias - EPAMIG (Machado, MG).

A fração de defeito PVA (preto, verde e ardido) foi homogeneizada e seca a $105^{\circ} \mathrm{C}$. 
Tabela 1. Características dos adsorbatos empregados

Adsorvente Natureza $\quad$ Massa molar $\lambda_{\text {máximo }}(\mathrm{nm})$

\begin{tabular}{llcc}
\hline $\begin{array}{l}\text { Azul de } \\
\text { Metileno } \\
\text { (AM) }\end{array}$ & $\begin{array}{l}\text { Corante } \\
\text { catiônico }\end{array}$ & 319,8 & 665 \\
$\begin{array}{l}\text { Vermelho } \\
\text { Reativo (VR) }\end{array}$ & $\begin{array}{l}\text { Corante } \\
\text { aniônico }\end{array}$ & 968 & 554
\end{tabular}

$\mathrm{AM}$<smiles>CN(C)c1ccc2nc3ccc(=[N+]([O-])[O-])cc-3sc2c1</smiles>

VR

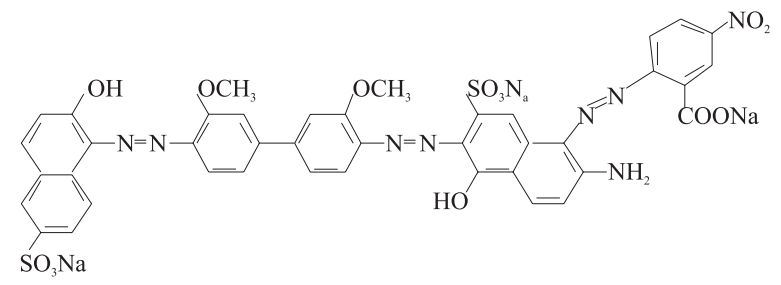

Preparação do carvão ativado a partir do defeito PVA do café

Os grãos de café (preto, verde e ardido) foram impregnados com $\mathrm{ZnCl}_{2}$ (Merck) na relação 1:1 (rejeito: $\mathrm{ZnCl}_{2}$, em massa), e colocados em estufa a $110^{\circ} \mathrm{C}$ por $24 \mathrm{~h}$ antes do processo de pirólise.

Os materiais foram, então, pirolisados e ativados por tratamento térmico controlado em formo tubular Sanchis sob fluxo de $100 \mathrm{~mL}$ $\min ^{-1}$ de $\mathrm{N}_{2}$.

A temperatura do forno foi elevada até $500{ }^{\circ} \mathrm{C}$, a uma taxa de $10{ }^{\circ} \mathrm{C} \mathrm{min}^{-1}$, sendo mantida nessa temperatura por $3 \mathrm{~h}$. O material carbonáceo (CA PVA) obtido foi lavado com solução de $\mathrm{HCl}$ 1:1 (HCl:água) para remoção de resíduos de $\mathrm{ZnCl}_{2}$ e desobstrução dos poros formados.

\section{Caracterização dos materiais}

Análise de área superficial (BET) e porosidade

As isotermas de adsorção e dessorção de $\mathrm{N}_{2}$ foram realizadas a $77 \mathrm{~K}$ em um equipamento Autosorb-1, Quantachrome. A amostra foi previamente tratada a $250{ }^{\circ} \mathrm{C}$ por $12 \mathrm{~h}$. A distribuição de tamanhos de poros foi calculada a partir da isoterma de adsorção de $\mathrm{N}_{2}$ usando o método BJH. A área superficial específica foi calculada utilizando a equação BET na região de baixa pressão $\left(\mathrm{p} / \mathrm{p}_{0}=0,200\right)$.

\section{Análise elementar (CHN) e teor de cinzas}

As amostras foram analisadas quanto aos teores de $\mathrm{C}, \mathrm{H}, \mathrm{N}$, em um aparelho Perkin Elmer PE 2400. O teor de oxigênio foi obtido por diferença. O teor de cinzas foi determinado pesandose $1 \mathrm{~g}$ de material em um cadinho de porcelana previamente tarado; em seguida, os materiais foram colocados em uma mufla e aquecidos até $550{ }^{\circ} \mathrm{C}$, onde foram mantidos até a calcinação completa do carvão.
Análise termogravimétrica (TG)

As análises foram realizadas em um analisador termomecânico Shimadzu-TMA50. As amostras foram aquecidas a uma taxa de $10{ }^{\circ} \mathrm{C} \mathrm{min}^{-1}$ sob um fluxo de ar, de 25 a $750{ }^{\circ} \mathrm{C}$.

\section{Microscopia eletrônica de varredura}

A morfologia dos materiais foi obtida por microscopia eletrônica de varredura (MEV), utilizando-se um aparelho Leo Evo 40XVP, usando uma tensão de $25 \mathrm{kV}$. A amostra foi colocada sobre a superfície do suporte de alumínio com fita de carbono dupla face e coberto com uma fina camada de ouro em um evaporador (Balzers SCD 050).

Espectroscopia na região do infravermelho

Os materiais foram analisados por espectroscopia na região do infravermelho com transformada de Fourier (FTIR), em um aparelho Digilab Excalibur, série FTS 3000 com faixa espectral de 400 a 4000 $\mathrm{cm}^{-1} \mathrm{e}$ resolução de $4 \mathrm{~cm}^{-1}$. As amostras foram preparadas em forma de pastilha de $\mathrm{KBr}$ ( $2 \mathrm{kBar}$ por $2 \mathrm{~min})$.

Cinética de adsorção

A cinética de adsorção foi investigada em temperatura ambiente $\left(25 \pm 1{ }^{\circ} \mathrm{C}\right)$ e $\mathrm{pH} 5,4$. Amostras de $10 \mathrm{mg}$ de carvão foram adicionadas a recipientes contendo $10 \mathrm{~mL}$ de solução $50 \mathrm{mg} \mathrm{L}^{-1}$ dos corantes (AM e VR) (Tabela 1). Alíquotas do sobrenadante foram retiradas em intervalos pré-determinados e a concentração do adsorvente determinada por espectofotometria UV-Visível (Biosystems, modelo SP-2000 UV).

\section{Isotermas de adsorção}

Para obtenção das isotermas de adsorção, $10 \mathrm{mg}$ dos materiais adsorventes foram colocados em contato com $10 \mathrm{~mL}$ das soluções de diferentes concentrações variando de 10 a $1000 \mathrm{mg} \mathrm{L}^{-1}$ e mantidas sob agitação por $24 \mathrm{~h}$ à temperatura ambiente $\left(25 \pm 1^{\circ} \mathrm{C}\right)$ e $\mathrm{pH} 5,4$. Em seguida, o material foi centrifugado e a concentração remanescente foi monitorada por UV-Visível (SP-2000) nos comprimentos de onda adequados para AM e VR (Tabela 1)

Calculou-se a quantidade de material adsorvido por unidade de massa do adsorvente $\mathrm{q}_{\mathrm{eq}}\left(\mathrm{mg} \mathrm{g}^{-1}\right)$ utilizando a Equação 1 .

$q_{e q}=\frac{\left(C_{o}-C_{e q}\right) V}{m}$

em que $C_{o}\left(\mathrm{mg} \mathrm{L}^{-1}\right)$ e $C_{e q}\left(\mathrm{mg} \mathrm{L}^{-1}\right)$ representam as concentrações inicial e no equilíbrio, respectivamente, $\mathrm{V}$ (L) o volume de adsorbato e $\mathrm{m}(\mathrm{g})$ a massa do material adsorvente.

As isotermas foram ajustadas aos modelos de isotermas de Langmuir e de Freundlich. Foi utilizado carvão comercial (Dinâmica) como referência.

\section{RESULTADOS E DISCUSSÃO}

\section{Caracterização dos carvões ativados}

Área superficial (BET)

A isoterma de adssorção/dessorção de $\mathrm{N}_{2}$ (Figura 1a) indicou elevada adsorção a baixas pressões de $\mathrm{N}_{2}$, evidenciando a formação de microporos.

A área superficial determinada pelo método BET foi de $516 \mathrm{~m}^{2} \mathrm{~g}^{-1}$. A análise da distribuição do volume de poros em função do diâmetro (Figura 1b) indicou que o CA PVA é principalmente constituído por microporos com diâmetro de 1,1 a 1,7 nm. 

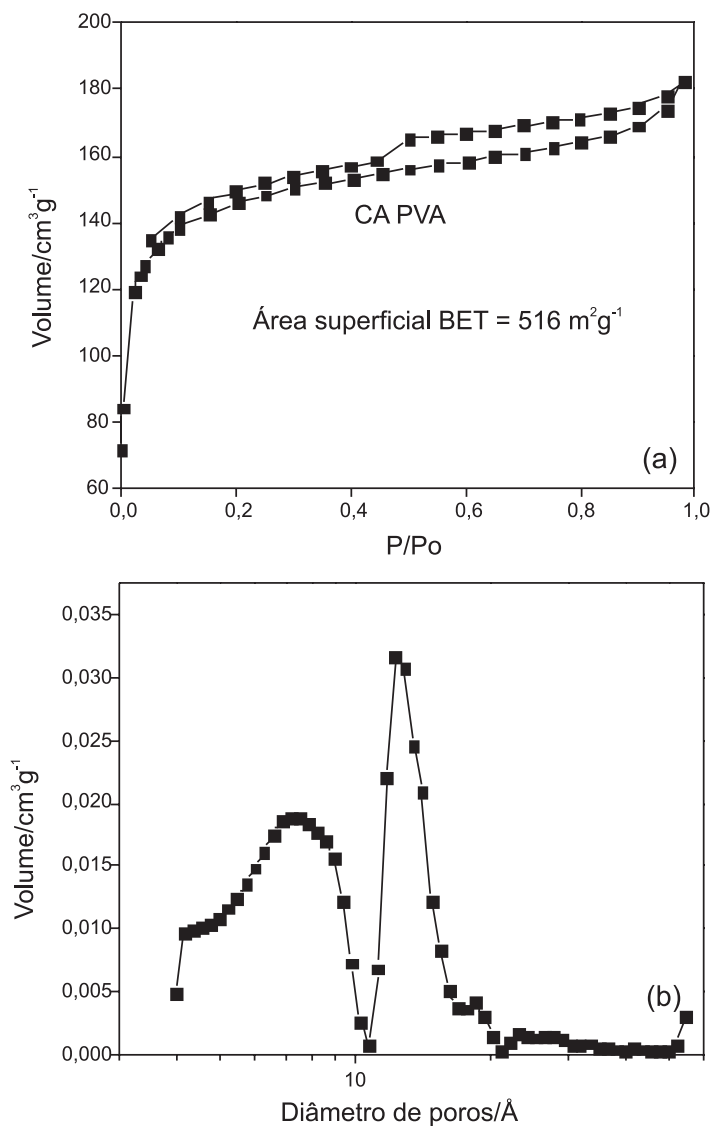

Figura 1. Isoterma de adsorção/dessorção de $N_{2}$ à 77 K para o CA PVA (a) e distribuição do volume de poros para o CA PVA (b)

\section{Análise elementar (CHN)}

O material de partida apresenta baixo teor de cinzas (4,33\%) que é um fator positivo para produção de carvão ativado (Tabela 2), visto que a matéria mineral causa um efeito dielétrico sobre o processo de adsorção adsorvendo, preferencialmente, água devido ao caráter hidrofílico. ${ }^{17}$

Porém, após a pirólise e ativação encontra-se um elevado teor de cinzas $(20 \%)$ que pode influenciar de forma negativa na capacidade de adsorção dos materiais. $\mathrm{O}$ aumento do teor de cinzas pode estar relacionado ao método de ativação e ao fato de os compostos inorgânicos presentes no material de partida ficarem retidos (oclusos ou ligados ao material carbonáceo) após o processo de pirólise, não sendo lixiviados no processo de lavagem. $\mathrm{O}$ aumento significativo da relação $\mathrm{C} / \mathrm{H}$ e a diminuição do teor de oxigênio nos processos de pirólise e ativação são bons indicadores da grande extensão do processo de carbonização. Esse processo ocorre com a liberação de compostos voláteis ricos em oxigênio e hidrogênio. $\mathrm{O}$ aumento na relação $\mathrm{C} / \mathrm{H}$ indica um aumento no grau de aromaticidade após o processo de ativação do material. ${ }^{18}$

Tabela 2. Análise elementar e teor de cinzas do precursor e do carvão ativado preparado por ativação com $\mathrm{ZnCl}_{2}$

\begin{tabular}{lcccccc}
\hline Materiais & $\mathrm{C}(\%)$ & $\mathrm{H}(\%)$ & $\mathrm{N}(\%)$ & $\mathrm{O}^{*}(\%)$ & $\mathrm{C} / \mathrm{H}$ & $\begin{array}{c}\text { Cinzas } \\
(\%)\end{array}$ \\
\hline $\begin{array}{l}\text { Defeito } \\
\text { PVA }\end{array}$ & 38,7 & 5,4 & 1,6 & 50,4 & 7,17 & 4,33 \\
$\mathrm{CA} \mathrm{ZnCl}_{2}$ & 66,98 & 3,53 & 1,9 & 27,59 & 18,9 & 20 \\
\hline
\end{tabular}

Análise termogravimétrica

A análise termogravimétrica do CA PVA foi obtida em ar com taxa de aquecimento de $10^{\circ} \mathrm{C} \mathrm{min}{ }^{-1}$. A curva TG é mostrada na Figura 1S (Material Suplementar).

Pode-se observar, pela análise térmica, que o primeiro declive de massa, próximo a $100{ }^{\circ} \mathrm{C}$ é decorrente da perda de umidade. A decomposição do CA PVA ocorre próximo de $450^{\circ} \mathrm{C}$. A porcentagem de resíduos foi de aproximadamente $20 \%$. Os resíduos são provenientes dos óxidos formados durante o processo de aquecimento em atmosfera oxidante. ${ }^{19}$

\section{Microscopia eletrônica de varredura}

A morfologia do CA PVA foi estudada por microscopia eletrônica de varredura (MEV), conforme mostrado na Figura 2.

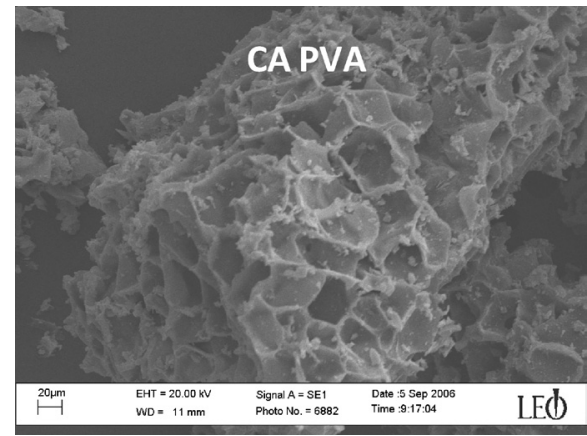

Figura 2. Micrografia obtida por MEV do CA PVA

A análise por MEV do precursor mostrou um material com estrutura fibrosa (Figura 2S, Material Suplementar). Após o processo de pirólise e ativação observa-se uma modificação na estrutura do precursor, com formação de poros em forma de crateras uniformes (tipo colméia). A análise de MEV por elétrons retroespalhados não mostra a presença de agregados contendo núcleos pesados. Esse resultado é um indicativo de que os óxidos metálicos formados devem estar distribuídos uniformemente no material.

\section{Espectroscopia na região do infravermelho}

No espectro do defeito PVA (Figura 3) a banda em $3400 \mathrm{~cm}^{-1}$ pode ser atribuída ao estiramento vibracional do grupo O-H de água. As absorções localizadas na região de 2930 até $2850 \mathrm{~cm}^{-1}$ são características de vibrações simétricas e assimétricas de grupos metilas e metilenos. A absorção situada em $1749 \mathrm{~cm}^{-1}$ é característica de estiramento vibracional de $\mathrm{C}=\mathrm{O}$ de carbonila que, juntamente com vibração de deformação axial da ligação $\mathrm{C}-\mathrm{O}$, que aparece como um ombro em $1168 \mathrm{~cm}^{-1}$, sugerem a presença tanto de ácidos carboxílicos como de ésteres ou $\delta$-lactonas ligados a grupos aromáticos. ${ }^{9}$ As bandas em 1640 e $1469 \mathrm{~cm}^{-1}$ são referentes ao estiramento vibracional $\mathrm{C}=\mathrm{O}$ e N-H de amidas. ${ }^{20}$ São observadas absorções entre 1000 e $1168 \mathrm{~cm}^{-1}$ referentes ao estiramento vibracional de C-O de álcoois. ${ }^{21}$

Após o processo de pirólise pode-se observar a diminuição ou até mesmo o desaparecimento de bandas referentes aos grupos funcionais presente no material de partida. O desaparecimento da banda em $2929 \mathrm{~cm}^{-1}$, atribuída aos estiramentos vibracionais simétricos e assimétricos de grupos $\mathrm{CH}$, evidencia a ocorrência da pirólise do material. As absorções em 1600 e $1480 \mathrm{~cm}^{-1}$ presentes em ambos os CAs são referentes ao estiramento $\mathrm{C}=\mathrm{C}$ de aromáticos. ${ }^{22}$

\section{Cinética de adsorção}

A Figura 4 ilustra a variação da acumulação dos adsorventes, 50 mg L $\mathrm{L}^{-1} \mathrm{AM}$ e VR na fase sólida $\left(\mathrm{q}_{\mathrm{eq}}\right)$ em função do tempo de contato com o adsorvente (CA PVA). Pode-se observar que inicialmente o 


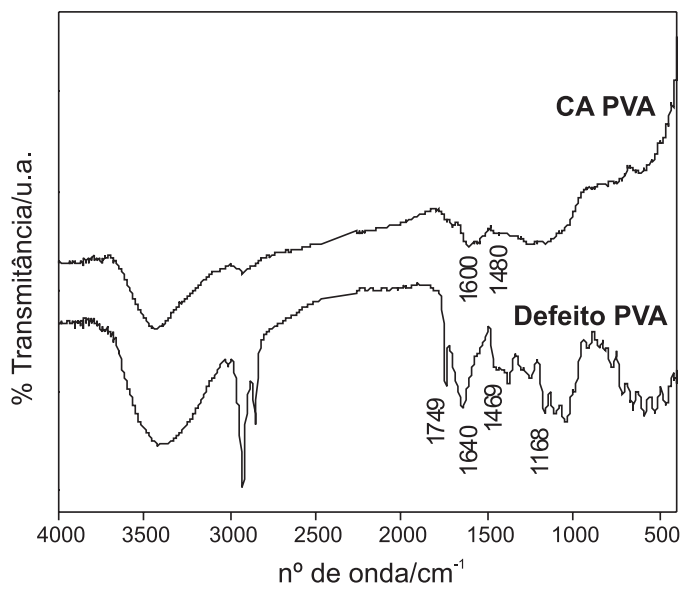

Figura 3. Espectro de infravermelho de transmitância obtida por FTIR do defeito PVA e do CA PVA

processo de adsorção é rápido, o que provavelmente está relacionado com os sítios de adsorção disponíveis na superfície do carvão, seguido de um processo mais lento. ${ }^{23} \mathrm{O}$ equilíbrio foi atingido após $15 \mathrm{~h}$, por isso, os materiais foram deixados em contato com a solução dos contaminantes por $24 \mathrm{~h}$.

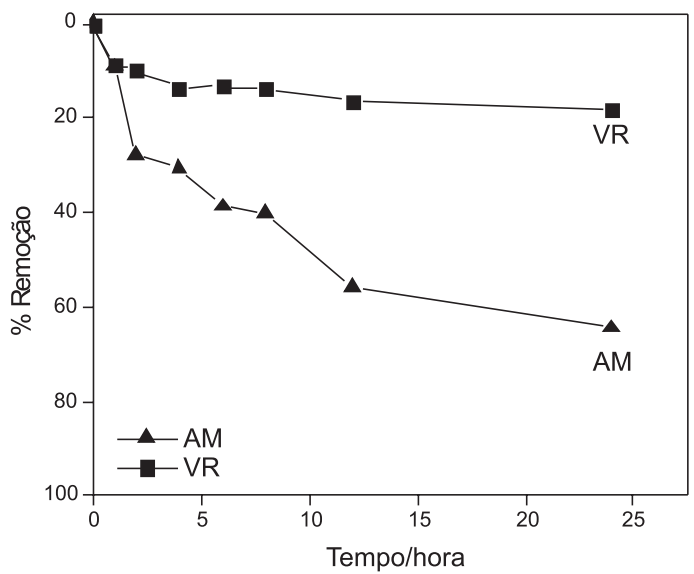

Figura 4. Cinética de adsorção de AM e RV no CA PVA (10 mg de material;

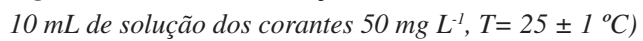

\section{Testes de adsorção}

Azul de metileno e vermelho reativo

Os resultados experimentais obtidos na adsorção de AM e VR pelo CA PVA, a partir de soluções com diferentes concentrações dos compostos orgânicos estão apresentados nas Figuras 5 e 6 . Foi utilizado o carvão ativado comercial Dinâmica (CAC) como referência.

Os dados de equilíbrio foram processados de acordo com as isotermas de Langmuir e Freundlich. Os parâmetros obtidos aplicando-se estes modelos aos dados experimentais são apresentados na Tabela 3.

Os resultados demonstram que o equilíbrio é mais bem descrito pelas isotermas de Langmuir, cujos coeficientes de correlação são elevados. Os valores de $\mathrm{q}_{\mathrm{m}}$ constante relacionada à capacidade máxima de adsorção de 102 e $42 \mathrm{mg} \mathrm{g}^{-1}$ para o AM e VR, respectivamente, estão condizentes com os máximos observados nas isotermas.

Para o AM a capacidade máxima de adsorção foi de $86 \mathrm{mg} \mathrm{g}^{-1}$, já pra o VR foi de $42 \mathrm{mg} \mathrm{g}^{-1}$. A diferença na capacidade de adsorção do VR, quando comparada ao AM, pode ser atribuída à diferença de

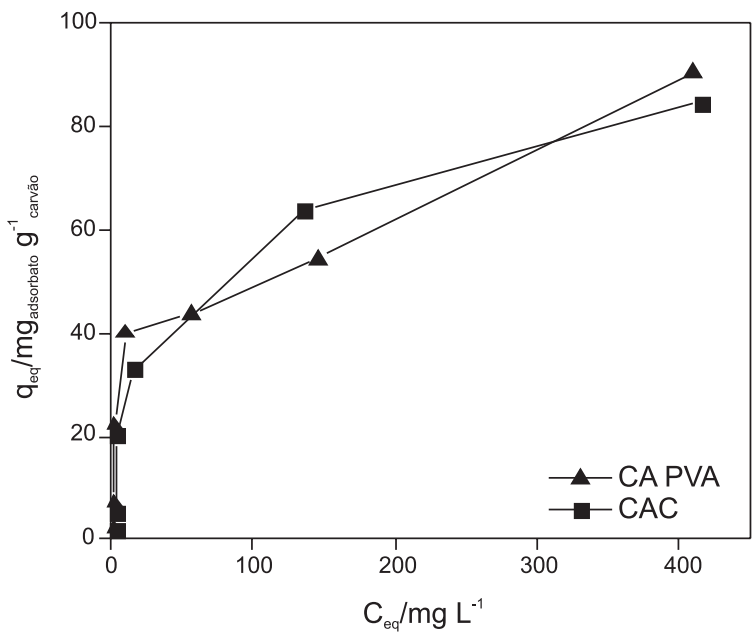

Figura 5. Isoterma de adsorção do AM para o CAC e CA PVA (10 mg de material; $10 \mathrm{~mL}$ de $\mathrm{AM}, \mathrm{T}=25 \pm 1{ }^{\circ} \mathrm{C}$ )

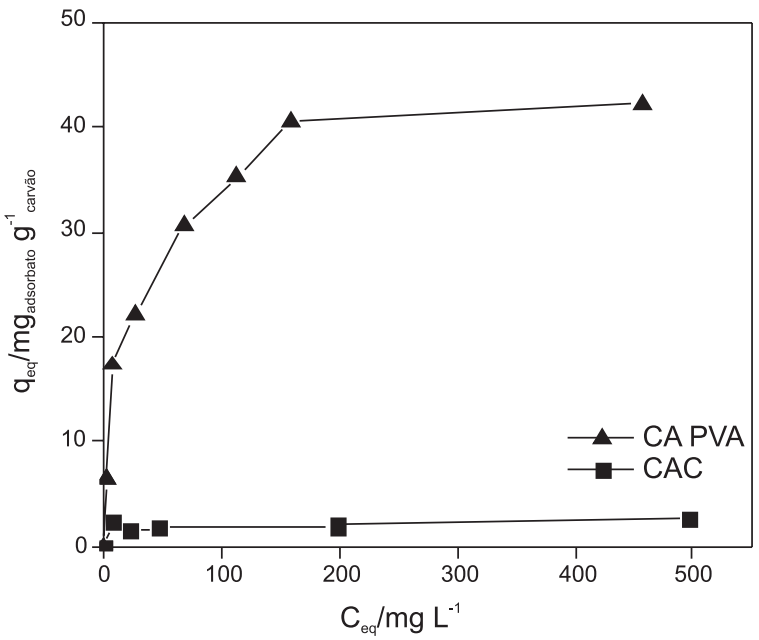

Figura 6. Isoterma de adsorção do VR para o CAC e CA PVA (10 mg de material; $10 \mathrm{~mL}$ de $V R, T=25 \pm 1{ }^{\circ} \mathrm{C}$ )

tamanho da molécula e ao número de grupos funcionais presentes em cada corante. ${ }^{24} \mathrm{~A}$ longa cadeia e estrutura molecular do VR foram desfavoráveis à sua adsorção, provavelmente devido à dificuldade de difusão e à orientação espacial sobre a superfície do material.

O CA PVA mostrou-se eficiente na remoção dos corantes quando comparado ao CAC.

\section{CONCLUSÃO}

O defeito PVA mostrou-se um bom precursor para produção de carvão ativado. O carvão obtido a partir do defeito PVA do café apresentou área superficial pequena quando comparada com os descritos na literatura, mas apresentou uma capacidade máxima de adsorção para os corantes, comparável à do carvão ativado comercial.

O fato do CA PVA apresentar capacidade máxima de adsorção mais elevada para o corante azul de metileno comparada à adsorção do corante têxtil vermelho reativo pode estar relacionado às cargas apresentadas pela superfície dos adsorventes e à habilidade das moléculas em acessar os poros do material adsorvente.

Os resultados mostram que os CAs produzidos a partir de defeito PVA mostraram-se potenciais adsorventes para contaminantes do meio aquoso, podendo ser utilizados como fonte alternativa para a produção de materiais adsorventes de baixo custo. 
Tabela 3. Parâmetros físico-químicos de adsorção obtidos a partir dos ajustes aos modelos de Langmuir e de Freundlich para os adsorbatos AM e VR a $25^{\circ} \mathrm{C}$

\begin{tabular}{|c|c|c|c|c|c|c|c|}
\hline \multirow[t]{2}{*}{ Adsorvente } & \multirow[t]{2}{*}{ Adsorbato } & \multicolumn{2}{|c|}{ Isoterma Langmuir } & \multirow[b]{2}{*}{$\mathrm{R}^{2}$} & \multicolumn{3}{|c|}{ Isoterma Freundlich } \\
\hline & & $\mathrm{q}_{\mathrm{m}}\left(\mathrm{mg} \mathrm{g}^{-1}\right)$ & $\mathrm{b}\left(\mathrm{L} \mathrm{mg}^{-1}\right)$ & & $1 / \mathrm{n}$ & $\mathrm{K}_{\mathrm{f}}\left(\mathrm{mg}^{1-1 / \mathrm{n}} \mathrm{L}^{1 / \mathrm{n}} \mathrm{g}^{-1}\right)$ & $\mathrm{R}^{2}$ \\
\hline \multirow[t]{2}{*}{$\mathrm{CAC}$} & $\mathrm{AM}$ & 100 & 0,02 & 0,95 & 0,51 & 5,01 & 0,80 \\
\hline & VR & 2 & 0,26 & 0,99 & 0,05 & 1,66 & 0,42 \\
\hline \multirow[t]{2}{*}{ CA PVA } & $\mathrm{AM}$ & 102 & 0,01 & 0,94 & 0,01 & 2,69 & 0,85 \\
\hline & VR & 42 & 0,05 & 0,99 & 0,42 & 4,67 & 0,98 \\
\hline
\end{tabular}

\section{MATERIAL SUPLEMENTAR}

No material suplementar, disponível em http://quimicanova.sbq. org.br, com acesso livre em formato PDF, são apresentadas a curva TG do carvão ativado (Figura 1S) e a microscopia eletrônica de varredura (MEV) do precursor (Figura 2S) para comparação.

\section{AGRADECIMENTOS}

À FINEP pelo financiamento (CAPQeLME) e à FAPEMIG, CAPES e ao CNPq pelo suporte financeiro e bolsas concedidas.

\section{REFERÊNCIAS}

1. Coelho, K. F.; Pereira, R. G. F. A.; Ciênc. Agrotec. 2002, $26,375$.

2. Oliveira, L. S.; Franca, A. S.; Mendonça, J. C. F.; Barros-Júnior, M. C.; LWT- Food Sci. Technol. 2006, 39, 235.

3. Borges, F. B.; Jorge, J. T.; Noronha, R.; Ciênc. Tecnol. Aliment. 2002, 22,158 .

4. http://www.casemg.com.br/download/CASEMG\%20Colheita\%20 Caf\%C3\%A9\%20-\%20Monte\%20Carmelo.pdf, acessada em Dezembro 2007.

5. Claudino, A.; Dissertação Mestrado, Universidade Federal de Santa Catarina, Brasil, 2003.

6. Kadirvelu, K.; Palanival, M.; Kalpana, R.; Rajeswari, S.; Biores. Technol. 2000, 74, 263.

7. Wu, F. C.; Tseng, R. L.; Juang, R. S.; J. Environ. Sci. Heal. A 1999, 34, 1753.

8. No, H. K.; Meyers, S. P.; Rev. Environ. Contam. Toxicol. 2000, 163, 1.
9. Guilarduci, V. V. S.; Mesquita, J. P.; Martelli, P. B.; Gorgulho, H. F.; Quim. Nova 2006, 29, 1226.

10. Schetino Jr., M. A.; Freitask, J. C. C.; Cunha, A. G.; Emmerich, F. G.; Quim. Nova 2007, 30, 1663.

11. Olivares-Marín, M.; Fernández-González, C.; Macías-García, A.; Gómez-Serrano, V.; Appl. Surf. Sci. 2006, 252, 5967.

12. Wigmans, T.; Carbon 1989, 27, 13.

13. Rocha, W. D.; Luz, J. A. M. da; Lena, J. C. de; Romero, O. B.; Esc. Minas 2006, 59, 409.

14. Moreno-Castilha, C.; Carrasco-mar'rin, F.; Lopez-Ramos, V.; AlvarezMerino, M. A.; Carbon 2001, 39, 1415.

15. Rodriguez-Reinoso, F.; Molina-Sabio, M.; Gonzalez, M. T.; Carbon 1995, 33, 15.

16. Bueno, C. I. C.; Carvalho, W. A.; Quim. Nova 2007, 30, 1911.

17. Castilla, M. C.; Tese de Doutorado, Universidade de Granada, Espanha, 2004.

18. Warhurst. A. M.; Fowler, G. D.; McConnnachie, G. L.; Pollard, J. T.; Carbon 1997, 35, 1039.

19. Gonçalves, M.; Guerreiro, M. C.; Bianchi, M. L.; Oliveira, L. C. A.; Pereira, E. I.; Dallago, R. M.; Ciênc. Agrotec. 2007, 31, 1386.

20. Boonamnuayvitaya, V.; Chaiya, C.; Tanthapanichakoon, S.; J. Chem. Eng. Jpn. 2004, 37, 1504.

21. Boonamnuayvitaya, V.; Sae-Ung. V.; Tanthapanichakoon, S.; Sep. Purif. 2005, 42, 159 .

22. Ahmad, A. L.; Loh, M. M.; Aziz, J. A.; Dyes Pigm. 2007, 75, 263.

23. Tsang, D. C. W.; Hu, J.; Liu, M. Y.; Zhang, W.; Lai, K. C. K.; Lo, I. M. C.; Water, Air, Soil Pollut. 2007, 184, 141.

24. Wong, Y. C.; Szeto, Y. S.; Cheung, W. H.; Mckay, G.; Langmuir 2003, 19,7888 . 


\section{PRODUÇÃO E CARACTERIZAÇÃO DE CARVÃO ATIVADO PRODUZIDO A PARTIR DO DEFEITO PRETO, VERDE, ARDIDO (PVA) DO CAFÉ}

Paulize H. Ramos*, Mário C. Guerreiro, Eliane C. de Resende e Maraísa Gonçalves

Departamento de Química, Universidade Federal de Lavras, CP 3037, 37200-000 Lavras - MG, Brasil

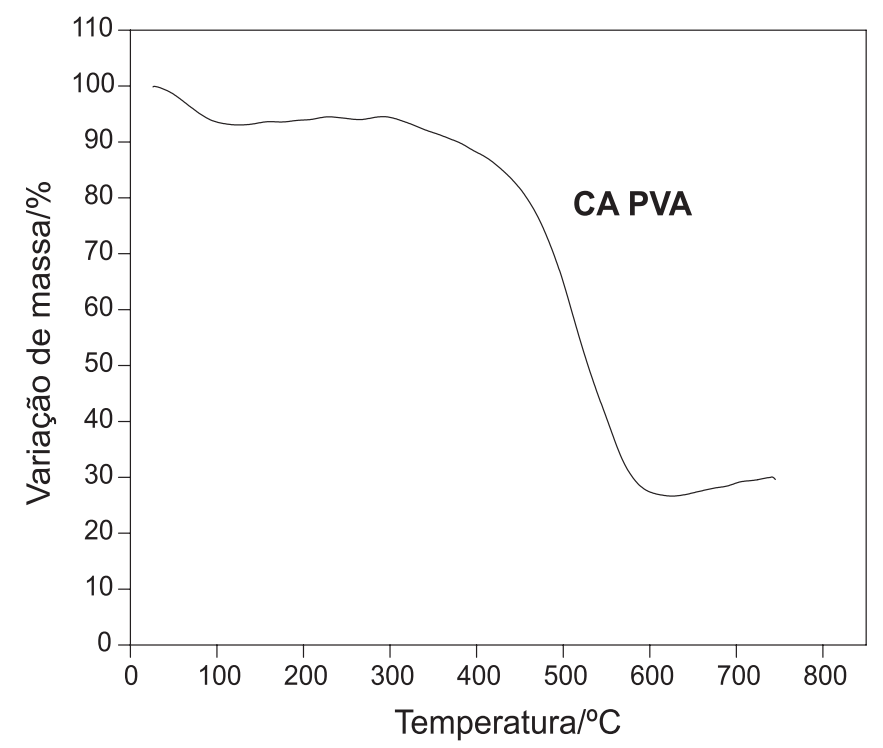

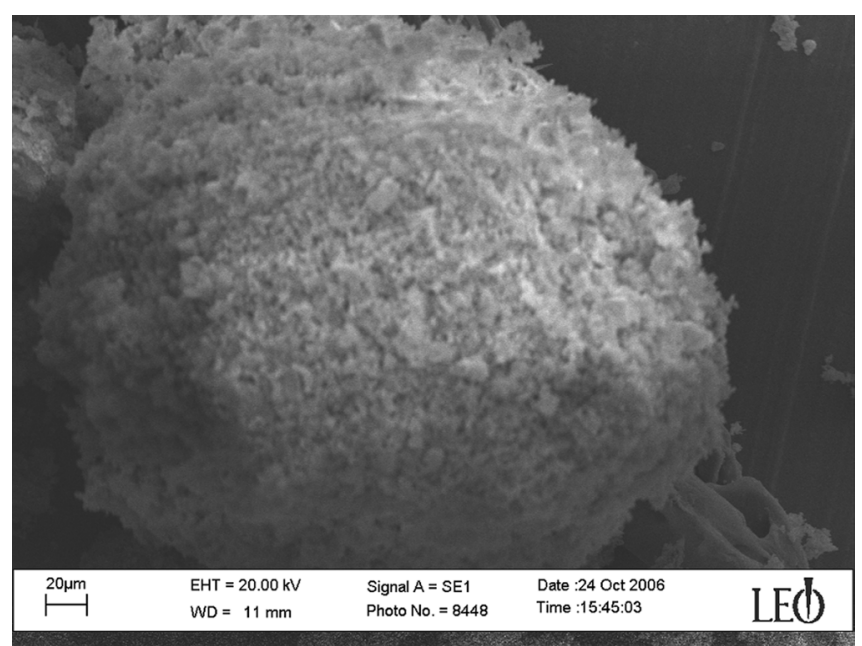

Figura 2S. Microscopia eletrônica de varredura (NEV) do precursor

Figura 1S. Curva TG do carvão ativado 